\title{
A regionalização da saúde no federalismo brasileiro
}

\author{
The regionalization of health in Brazilian federalism
}

La regionalización de la salud en el federalismo brasileño

Ana Cristina Carvalho Curvina ${ }^{1}$

Resumo: Objetivos: A abordagem sobre a regionalização, diretriz constitucional organizadora do Sistema Único de Saúde (SUS), teve como base os fundamentos dispostos no ordenamento constitucional e seus conceitos, com vistas a verificar a efetividade da regionalização no sistema federativo brasileiro. Metodologia: Foi abordado, também, o conceito de descentralização, processo que possibilitou a transferência do poder decisório da esfera federal para os estados e municípios. A partir da revisão da literatura e da legislação federal, foram analisadas as implicações das relações intergovernamentais para a efetivação da regionalização das ações e serviços de saúde. Resultados: A estrutura institucional do SUS demonstra que a coordenação da regionalização é orientada pelo modelo do federalismo, com atribuições e competências definidas na Constituição Federal e na Lei Orgânica da Saúde, para os três entes federados. Conclusão: Concluiu-se que a regionalização no SUS representa o federalismo cooperativo, expresso nas relações intergovernamentais, com base normativa bem definida, entretanto, ainda persistem alguns fatores críticos, como a heterogeneidade da estrutura federativa brasileira, a cultura política do país, as responsabilidades do poder executivo municipal, e a gestão da cooperação entre os entes no âmbito regional.

Palavras-chave: Federalismo. Descentralização. Regionalização.

\begin{abstract}
Objective: The approach to regionalization, constitutional guideline organizer of the Unified Health System (SUS), was based on the foundations laid in the constitutional framework and its concepts in order to verify the effectiveness of regionalization in the Brazilian federal system. Was approached, too, the concept of decentralization, a process that allowed the transfer of decision-making power of federal government to states and municipalities. Methods: From the literature review and federal law, we analyzed the implications of intergovernmental relations established for effective regionalization of health services and actions. Results: The institutional structure of SUS shows that coordination of regionalization is driven model of federalism, with powers and tasks defined by the Constitution and the Organic Law of Health, for the three counties. Conclusion: It was concluded that regionalization is the SUS cooperative federalism expressed in intergovernmental relations, based normative well defined, however, there are still some critical factors such as the heterogeneity of the Brazilian federal structure, the political culture of the country, the responsibilities of the municipal executive, management and cooperation among entities within the region.
\end{abstract}

Keywords: Federalism. Decentralization. Regionalization.

\footnotetext{
${ }^{1}$ Graduada em Psicologia pelo Uniceub, Centro Universitário de Brasília. E-mail: accurvina@hotmail.com
} 
Resumen: Objectivos: El enfoque sobre la regionalización, directrices constitucionales organizadora del Sistema Único de Salud (SUS), se basó en las bases preparadas en el marco constitucional y sus conceptos, con el fin de verificar la eficacia de la regionalización en el sistema federal de Brasil. Metodología: Se discutió también el concepto de descentralización, un proceso que permitió la transferencia del poder de toma de decisiones desde el nivel federal a los estados y municipios. A partir de la revisión de la literatura y de la legislación federal, se analizaron las implicaciones de las relaciones intergubernamentales para la realización de la regionalización de las acciones y servicios de salud. Resultados: estructura institucional SUS demuestra que la coordinación de la regionalización es por el modelo federalismo, las competencias y misiones definidas en la Constitución y la Ley Orgánica de Salud, para los tres condados. Conclusión: Se concluye que la regionalización en el SUS es federalismo cooperativo expresado en las relaciones intergubernamentales sobre la base de reglas bien definidas, sin embargo, todavía hay algunos factores críticos, tales como la heterogeneidad de la estructura federal de Brasil, la cultura política del país, las responsabilidades el ejecutivo municipal y la gestión de la cooperación entre las entidades a nivel regional.

Palabras clave: Federalismo. Descentralización. Regionalización.

\section{Introdução}

De acordo com a Constituição Federal de 1988, a estrutura federativa do Brasil é formada por três esferas autônomas de governo: União, Estados e Municípios.

A instituição do Sistema Único de Saúde (SUS) representa o resultado do reconhecimento da saúde como direito social. Assim, a Constituição Federal de 1988 conferiu ao Estado brasileiro a responsabilidade de garantir a promoção, proteção e recuperação da saúde, com acesso universal, gratuito e igualitário.

A organização institucional do SUS reproduz a estrutura trina dos três níveis de governo, legitimados para legislar concorrente e suplementarmente (CF, art. 24, XII, § $2^{\circ}$ e $3^{\circ}$ ), sobre a saúde em seus territórios, com atribuições e competências definidas na Lei Orgânica da Saúde (Lei nº 8.080/90).

O art. 198 da Constituição Federal estabelece as diretrizes do Sistema Único de Saúde: (a) a descentralização, com direção única em cada esfera de governo, (b) o atendimento integral, (c) e a participação da comunidade (1).

A descentralização, processo político-administrativo, esteve presente na reforma sanitária brasileira como forma de racionalizar e imprimir maior eficiência ao sistema de saúde, ocasionando a modificação na concentração de serviços, poder decisório, responsabilidades e recursos financeiros, até então centralizados no nível federal, para os estados e, principalmente, para os municípios. 
A regionalização, presente nos princípios do SUS, é compreendida como um processo político que evolve as relações intergovernamentais na definição de organização das ações e serviços de saúde num espaço geográfico, articulados em níveis de complexidade da rede de atenção à saúde, para garantir a integralidade da assistência à saúde.

A descentralização e a regionalização são princípios organizativos político-territoriais do SUS, que integram um conjunto de ações e serviços de saúde numa rede regionalizada e hierarquizada, sob gestão descentralizada com direção única em cada esfera de governo.

O debate sobre a regionalização da saúde vem se intensificando desde 1980, com a definição de propostas para modelos assistenciais, pautados na organização regional, visando garantir o acesso da população aos serviços de saúde. Desde então, ocorreram sucessivas normatizações para 0 enfrentamento das dificuldades conceituais e operacionais, com evolução no debate, porém, ainda permanecem algumas dificuldades para efetivar a regionalização da saúde, que requer mecanismos e instrumentos de interação e pactuação federativa entre as três instâncias de governo.

Portanto, este artigo tem como objetivo analisar a regionalização no SUS, na perspectiva federativa, buscando verificar a influência da cooperação intergovernamental no fortalecimento desta estratégia.

Para fundamentar a análise proposta, são revisados os referenciais teóricos sobre o tema, partindo da visão geral dos fundamentos do federalismo, o SUS na estrutura federativa brasileira, e os conceitos de descentralização e regionalização, finalizando com a discussão de alguns fatores críticos.

Verificar a influência do federalismo na implementação da diretriz da regionalização na política de saúde, nos termos das relações intergovernamentais instituídas, foi a tônica da revisão da literatura sobre o tema desde a criação do SUS na Constituição Federal, perpassando pelas normativas instituídas que sugeriram que a eficácia da regionalização depende das relações intergovernamentais estabelecidas na estrutura federativa brasileira para a organização das ações e serviços de saúde nas regiões de saúde.

Dessa forma, o estudo foi orientado pela revisão dos fundamentos do federalismo, como forma de organização do Estado, e as características do federalismo cooperativo; e 
pelas bases jurídico-institucionais, presentes no ordenamento constitucional que orientam a organização da regionalização da saúde no federalismo brasileiro.

\section{Federalismo brasileiro}

O federalismo, forma de organização do Estado, surgiu em 1787, com a Constituição dos Estados Unidos da América. O modelo do federalismo norte-americano foi copiado pelos demais países. O federalismo implantado nestes moldes converge, no todo ou em parte, para uma dualidade de competências, isto é, se caracteriza pela coexistência de, no mínimo, dois centros constitucionais de governo autônomos, atuando sobre um mesmo território e uma mesma população. (2).

O federalismo foi expresso em dois modelos: competitivo e cooperativo. O primeiro desenvolvido a partir do ideal de liberalismo norte-americano; e o segundo, a partir do ideal igualitário da Alemanha (3).

A formação dos modelos do federalismo dá uma idéia de aparente contrariedade: um salientando mais o princípio social e o outro, o princípio liberal; um favorecendo as relações associativas, de solidariedade e de colaboração, outro reforçando a dualidade de competências, limitando a ingerência da União nas políticas locais.

A multiconfiguração do federalismo decorre da distribuição de competências, mediante o emprego de algumas técnicas. A atribuição de competências é o meio de repartir as funções do Estado entre os seus órgãos, e são classificadas em: legislativa ou normativa; material ou executiva; e jurisdicional. No que diz respeito à caracterização do federalismo, há a repartição das competências entre os entes federados, em especial, as funções legislativas e materiais ou executivas, que permitem a existência do autogoverno (4).

Quanto à forma da divisão das matérias entre os entes federados, são empregadas técnicas de repartição horizontal ou vertical. A divisão horizontal, a técnica clássica, consiste em dividir em compartimentos as competências da União e dos Estados. Nesse sistema dualista, inexiste a concorrência de competências. Na repartição vertical algumas matérias são atribuídas conjuntamente à União e aos Estados, podendo ser: (a) cumulativa, onde todos os entes podem dispor sobre a matéria; (b) e não cumulativa, onde se reserva à União o poder de editar normas gerais, principiológicas, e aos estados a edição de normas complementares. 
No Brasil, a Constituição Federal de 1988, estabeleceu o federalismo como a forma do Estado brasileiro, inovando ao incluir os municípios na condição de entes federados, a saber:

Art. 1ำ A República Federativa do Brasil, formada pela união indissolúvel dos Estados e Municípios e do Distrito Federal, constitui-se em Estado democrático de direito e tem como fundamentos:

I. a soberania;

II. a cidadania;

III. a dignidade da pessoa humana;

IV. os valores sociais do trabalho e da livre iniciativa;

V. o pluralismo político (BRASIL, 1988).

Para Meirelles (5), a inserção dos Municípios, compondo com os Estados e a União a estrutura federativa trina do país, significou a consolidação do poder local na organização do Estado brasileiro, propiciando a transferência de encargos e recursos para os governos municipais responsabilizarem-se pelo provimento de bens e serviços aos cidadãos.

A Constituição Federal de 1988, ao instituir o federalismo cooperativo no Brasil (arts. 23 e 24), definiu as competências comuns e concorrentes dos entes da Federação, de forma que colaborem para a execução das tarefas determinadas. Na cooperação, há dois momentos de decisão: o primeiro, em nível federal, de forma centralizada, quando as medidas a serem adotadas são determinadas, uniformizando a ação de todos os poderes competentes; o segundo se dá em nível estadual ou municipal, de forma descentralizada, quando o ente federado adapta a decisão tomada em conjunto à sua realidade (ABRUCIO, 1998).

De acordo com a Constituição Federal, a distribuição de competências entre os entes está estruturada nas técnicas de repartição horizontal e vertical. Assim, na repartição horizontal são distribuídas competências privativas, materiais e legislativas, entre a União, estados e municípios, enumerando as competências da União e dos municípios, e reservando aos estados a competência remanescente (arts. 21, 22 e 25).

$\mathrm{Na}$ repartição vertical, são atribuídas competências materiais comuns a todos os entes federados, e competências legislativas concorrentes para a União e estados (art. 24). E ao Distrito Federal, são atribuídas as competências dos estados e municípios (art. $\left.32, \S 1^{\circ}\right)$.

Há duas possíveis formas de federalismo cooperativo: o autoritário e o democrático. O primeiro caracteriza-se por uma cooperação desigual, com índole centralizadora e 
compressiva das autonomias estaduais, vulnera o princípio democrático e ignora as Casas do Congresso e as Assembleias dos estados. O federalismo cooperativo democrático é consentido e não imposto, e coloca o poder diretamente ligado aos valores democráticos de governo. A relação entre o poder federal e os poderes estaduais se dá sob a proteção da Constituição Federal, de forma a eliminar o autoritarismo e promover a confiança e a solidez do sistema perante os governados.

\section{O SUS no federalismo brasileiro}

O reconhecimento da saúde como direito social no Brasil, positivado na Constituição Federal de 1988, atribui ao Estado o encargo de atuar para a garantia da promoção, proteção e recuperação da saúde e o acesso universal, gratuito e igualitário a ações e serviços públicos de saúde.

Nesse contexto, foi instituído o Sistema Único de Saúde (SUS), a fim de assegurar os meios necessários à efetivação do direito à saúde no Brasil.

A forma das relações entre os entes federados é que mostra o funcionamento do Estado. Depende da disposição e do interesse dos vários governos em cooperar e da capacidade do governo central em estimular ou impor regras e programas que impliquem alguma forma de coordenação entre as atividades de estados e municípios (REVERBEL, 2012).

O SUS, instituição criada pelo Poder Constituinte, reproduz a disposição tríplice, característica do Estado federal brasileiro, legitimando a autonomia dos três níveis de governo - federal estadual e municipal - na gestão das ações e serviços de saúde em seus territórios. (6).

As Leis Orgânicas da Saúde (LOS), Lei n. 8.080/1990 e Lei n. 8.142/1990, cumprem o papel de veiculadoras de normas gerais sobre o sistema de saúde.

Assim, a Constituição Federal e a Lei Orgânica da Saúde determinaram o dever dos entes federados na área da saúde, e delimitaram a expressão da estrutura federativa nacional na área da saúde, ao determinarem o dever de todos os entes federados de atuarem na promoção, proteção e recuperação da saúde, com autonomia de cada esfera de governo para a gestão do sistema nos limites do seu território. 
A LOS estabelece o papel das esferas de governo na proteção e defesa da saúde, orientando suas respectivas atribuições e competências, e determina, em seu artigo 9º, que a direção do SUS deve ser única, conforme previsto no inciso I do artigo 198 da Constituição Federal.

As relações intergovernamentais se processam entre os três níveis de governo, tanto vertical quanto horizontalmente, isto é, entre a União e os Estados; entre a União e os Municípios; entre o Estado e os Municípios; os Estados entre si; e os Municípios entre si.

A Constituição Federal de 1988, ao atribuir competências comuns aos entes federados, estabeleceu que esses entes devem atuar em conjunto, compartilhando as ações referentes ao cuidado da saúde (art. 23, II). A repartição concorrente da competência legislativa (art. 24) se aplica na produção de normas sobre o SUS, pois a União, enquanto gestora nacional, coordenadora do sistema, é limitadora da atividade legislativa dos demais entres. Aos Estados cabe a edição das normas complementares, necessárias à implementação regional do SUS, e aos Municípios, cabe a normatização dos aspectos inerentes às suas peculiaridades locais

A Lei 8.080/90 enfatiza a descentralização político-administrativa, na forma da municipalização das ações e serviços e públicos de saúde, o que significa redistribuição de poder e competências.

Assim, a citada lei, estabelece no Capítulo IV, Seção I, Art. 15 ao 18, as atribuições comuns e as competências específicas a serem exercidas pela União, Estados, Distrito Federal e Municípios, na gestão do SUS, nos respectivos âmbitos administrativos.

O processo de descentralização em saúde no Brasil envolve não apenas a transferência de serviços, mas também de responsabilidades, poder e recursos da esfera federal, para os estados e municípios (7).

Complementar às regras político-administrativas do federalismo no sistema de saúde, a Lei n. 8.142/90 regulamentou a divisão dos recursos correspondentes, e estabeleceu o regime de transferências obrigatórias de recursos federais para os estados, municípios e Distrito Federal.

O modelo brasileiro de descentralização do SUS pode ser considerado como um exemplo bem sucedido de coordenação intergovernamental na condução da política social, com articulação das ações nos vários níveis de governo, por meio da utilização de comissões intergovernamentais. Esse sistema tem tido êxito, principalmente, devido aos 
vários anos de mobilização e participação ativa dos profissionais e associações ligados à área da saúde (8).

A concretização das relações intergovernamentais na implementação do SUS ocorreu em dois períodos distintos: com a implantação do sistema de saúde, quando houve a descentralização político-administrativa para os Municípios, movimento conhecido como municipalização; e no segundo momento, que perdura até os dias atuais, marcado pela instituição da estratégia da regionalização.

\section{Descentralização e regionalização: conceitos}

Após a Constituição Federal de 1988 uma tendência descentralizadora passou a fazer parte da maioria das políticas sociais no Brasil, que passou por períodos de maior ou menor intensidade e avanços.

Uma importante estratégia para a implantação do SUS foi a descentralização, um processo de natureza político-administrativa, que decidiu pela transferência de poder decisório, de gestão e de recursos financeiros, antes concentrado nas esferas federal, para os Estados e, principalmente, para os Municípios.

A história das políticas de saúde no Brasil segue um padrão de alternância entre o centralismo, predominante até os anos 90, e descentralização, instaurada formalmente com as Leis Orgânicas da Saúde: Leis 8.080/90 e 8.142/90.

A descentralização da saúde é uma construção política e social, com fortes influências culturais e muita complexidade, sem impedimento de que tenha acumulado importantes avanços. A sua implantação foi calcada em normas operacionais emanadas pelo gestor federal, colecionando críticas e ao mesmo tempo demonstrando certa progressão qualitativa (9).

Nos termos da Lei ํㅜ 8.080/90, a descentralização dos serviços para os municípios foi associada à regionalização e hierarquização da rede de serviços de saúde.

O arcabouço da descentralização da saúde proposto nas referidas Leis Orgânicas da Saúde teve como marco legal a edição das Normas Operacionais Básicas (NOB), responsáveis pelo detalhamento operacional, com foco na descentralização das ações e serviços, financiamento, organização de serviços, e o relacionamento entre as esferas de gestão. 
A descentralização da saúde na década de 1990 suscitou tensões e contradições, derivadas dos diferentes interesses dos municípios, dos estados e da União, dentre eles: (a) o descompasso entre atribuições e recursos; (b) o aumento da competição entre estados e municípios por recursos cada vez mais escassos; (c) as dificuldades históricas do modelo centrado nas práticas curativas e de alto custo, com baixo foco na promoção da saúde; (d) perfil dos municípios brasileiros caracterizados por dispersão, baixa população, qualificação precária, baixo dinamismo econômico; (e) e insuficiente articulação com outras políticas públicas de desenvolvimento econômico e social (9).

$\mathrm{Na}$ interpretação de Machado (10), um aspecto importante na era das Normas Operacionais Básicas (NOB) foi a transição dos modelos de descentralização, de uma forma tutelada e convenial para a descentralização com regionalização, com resgate do papel dos estados e partilha definida das funções dos entes federativos, sem abrir mão da forte regulação federal.

Outros conflitos do processo de descentralização da saúde são registrados, como a ênfase municipalista evidente nas NOB iniciais, que se chocava com uma racionalidade de base regional; o excesso e a complexidade das regras, por um lado, e as lacunas normativas, de outro; a ausência de uma política consequente de investimentos no setor; a desconsideração da diversidade macro e mesorregional e das especificidades das regiões metropolitanas na formulação da política; a insuficiente articulação com outras políticas públicas de desenvolvimento econômico e social (10).

\section{Sobre a regionalização da saúde}

Conforme enunciado na Constituição Federal de 1988 e na Lei no 8.080 de 1990, a regionalização configura-se como uma estratégia para organização das ações e serviços públicos de saúde, estando associada à ideia de hierarquização e níveis de complexidade.

A regionalização do SUS constitui estratégia prioritária para garantir o direito saúde, reduzir desigualdades sociais e territoriais, promover a equidade e a integralidade da atenção, racionalizar os gastos e otimizar os recursos, e potencializar o processo de descentralização.

A Constituição Federal de 1988 determina que "as ações e serviços públicos de saúde integram uma rede regionalizada e hierarquizada, e constituem um sistema único, 
organizado de acordo com as diretrizes de descentralização, atendimento integral e participação da comunidade" (1).

Desde 1986, mas principalmente a partir da X Conferência Nacional de Saúde, o tema da Regionalização vem sendo tratado e amplamente discutido nesses espaços. Na $X$ Conferência, o tema principal foi o fortalecimento da territorialização, fazendo com que as secretarias estaduais de saúde investissem na regionalização e promovessem a descentralização. A XI Conferência Nacional de Saúde, por sua vez, reforçou a necessidade de uma discussão efetiva entre os três entes federados e suas instâncias colegiadas sobre a regionalização da saúde. A XII Conferência Nacional de Saúde, realizada no ano de 2003, trouxe um documento consolidando a necessidade de aprimoramento da Regionalização.

$\mathrm{Na}$ década de 1990, com a edição da Lei no 8.080 e da NOB/93, iniciou-se a construção de gestão partilhada, quando o setor saúde apresentou inovações importantes no campo das relações intergovernamentais consideradas fundamentais à implantação do SUS (9).

Apesar de a regionalização estar prevista na Constituição Federal de 1988 e nas normativas, como mecanismo de descentralização, integralidade e de hierarquização da saúde, é apenas com a instituição da NOAS, em 2001, que a regionalização passa a ganhar significado e peso dentro do sistema.

Nos anos 2000, após os sucessivos ciclos de descentralização, ocorridos sob forte indução e regulação federal, a regionalização passou a destacar-se como uma estratégia prioritária no âmbito da política nacional de saúde (8)

A regionalização é uma diretriz do SUS e um eixo estruturante do Pacto de Gestão, e deve orientar a descentralização das ações e serviços de saúde e os processos de negociação e pactuação entre os gestores. (11).

Com a edição do Pacto pela Saúde, em 2006, destaca-se o fim do processo cartorial de habilitação, substituído pela formalização de termos de compromisso de gestão, que definiram as responsabilidades e compromissos de gestão assumidos por cada esfera de governo (9).

A regionalização orienta o processo de descentralização das ações e serviços de saúde e os processos de negociação e pactuação entre os gestores. 
O principal objetivo da regionalização é ampliar o acesso da população às ações e serviços de saúde de forma compartilhada e cooperativa e dessa forma contribuir para a qualificação do SUS.

A regionalização, importante ferramenta operacional da descentralização, se configurou como diretriz organizativa e eixo prioritário das políticas de saúde, com a consolidação de marcos conceituais e dos instrumentos de planejamento regional.

A regionalização da saúde tem como pressupostos a territorialização, a flexibilidade, a cooperação, a cogestão, o financiamento solidário, a subsidiariedade e o controle social (11).

A atual concepção de regionalização deve orientar a descentralização das ações e serviços de saúde e os processos de planejamento e pactuação entre os entes federados, objetivando garantir acesso resolutivo, integral e com qualidade.

A implementação da regionalização da saúde pressupõe a organização dos serviços de saúde em determinado espaço geográfico - região de saúde, visando o acesso e a integralidade da atenção à saúde.

O Pacto pela Saúde, norma editada em 2006, ampliou o conceito de região de saúde trazido anteriormente pela NOAS, propondo a substituição da natureza formal-burocrática com foco na capacidade instalada dos serviços e nos limites físicos dos municípios. Foi dado foco para as diversidades e as identidades culturais, sociais e econômicas da população, tendo região de saúde como "recortes territoriais inseridos em espaços geográficos contínuos, a partir de identidades culturais, econômicas e sociais, de redes de comunicação e infra-estrutura de transportes compartilhados do território (8).

A edição do Decreto n. 7.508/2011 (12) reforça o conceito de região de saúde proposto no Pacto pela Saúde, destacando a necessidade de integrar a organização, planejamento e a execução de ações e serviços de saúde.

As definições trazidas no Decreto n. 7.508/2011 representam as atuais orientações operacionais da regionalização, com a regulamentação da estrutura organizativa do SUS, e a articulação entre os entes federados, dentre outros aspectos; com a finalidade de garantir maior segurança jurídica na fixação das responsabilidades dos entes, na organização das ações e serviços de saúde ofertados nas regiões de saúde e organizados em redes de atenção. 
Nesse contexto, os serviços de saúde passam a ser organizados de forma compartilhada pelos entes federados, que saem da gestão individual para a gestão de interesse regional, fazendo ressaltar a cooperação e os deveres constitucionais na relação federativa para o setor saúde.

As diversas orientações normativas para a regionalização da saúde foram sofrendo importantes alterações, a partir da dinâmica do funcionamento das relações federativas, e com a oferta de consolidação de processos e mecanismos de cooperação e coordenação necessárias para efetivar a regionalização (9).

Assim, a regionalização da saúde é resultado de maturação política e institucional do SUS, representando o exercício do federalismo cooperativo.

\section{Discussão}

O modelo institucional do SUS proposto na Constituição Federal e na Lei Orgânica da Saúde, expressa o federalismo brasileiro na área da saúde, reproduzindo sua disposição tríplice, com a definição das três esferas correspondentes aos entes federados na gestão da saúde.

Ao longo do tempo, esse modelo foi aprimorado pelas normativas, que estabeleceram regras para o funcionamento do sistema de saúde, na perspectiva de regulamentar as relações intergovernamentais, baseadas em pactos específicos.

É importante considerar o ritmo da implantação da descentralização em saúde no Brasil, orientado pelas transferências de serviços públicos; responsabilidades e atribuições; recursos financeiros; e poder decisório sobre a política de saúde.

Quanto à regionalização, responsável pela organização das ações e serviços de saúde no território, caracteriza-se como um processo político mais amplo, pois sua consolidação está relacionada às relações governamentais entre os entes federados.

A efetivação da regionalização, não foi bem sucedida na década de 90 , resultando em disputas entre os governos estaduais e municipais por recursos e pelo comando de serviços, sem atingir a relação de cooperação entre os entes (9).

Tal fato justifica as diversas normativas instituídas, na perspectiva de definir as responsabilidades dos gestores do SUS nas três esferas de governos, na assunção de compromissos e atribuições de forma cooperativa. Outro fator preponderante neste 
cenário, e discutido ao longo do tempo, refere-se aos mecanismos de pactuação federativa, necessário na estrutura do sistema de saúde, para garantir o estabelecimento de compromissos entre as esferas de governo.

A organização do SUS de forma regionalizada pelos entes federados, precisa da definição das competências comuns e interdependentes na saúde pelos entes federados. A implementação da regionalização exige observar o princípio da predominância de interesse, a partir da competência concorrente dos entes federados em matéria de saúde.

A eficácia da regionalização da saúde no SUS requer conhecer as mudanças das negociações e conflitos intergovernamentais em saúde, na coordenação federativa dos objetivos da política de saúde, nas diferentes realidades territoriais e sociais (8).

A legislação do SUS que define a relação interfederativa na regionalização determina as competências das três esferas de governo em matéria de saúde, sendo necessária a cooperação entre os entes federados para garantir a efetividade do direito à saúde da população.

A organização dos serviços de saúde não se esgota em cada esfera de governo, pois o direito à saúde se efetiva numa rede de atenção à saúde, que é organizada de forma cooperativa pelos entes federados.

O sistema de saúde, apesar de submetido à coordenação do governo federal, se pauta pela descentralização, possibilitando a cooperação de esforços e a participação dos entes estaduais e municipais na formulação da política nacional, verificando-se de forma implícita o princípio democrático e federativo.

Vale destacar, portanto, o arcabouço do modelo institucional do SUS, que garante a participação dos três entes federados na formulação da política, por meio da articulação entre a atuação: (a) dos gestores do sistema em cada esfera de governo; (b) das instâncias de negociação e decisão das Comissões Intergestores Tripartite (no âmbito nacional), Bipartite (no âmbito estadual), e Regionais (em cada região de saúde); (c) dos conselhos de representação dos secretários de saúde estaduais e municipais (CONASS e CONASEMS); (d) e conselhos de saúde no âmbito nacional, estadual e municipal.

Verifica-se nesse contexto, a complexidade do SUS, com uma vasta formulação teórica que, se implementada na prática traz a possibilidade de uma atuação coordenada e integrada dos serviços públicos de saúde. 
Entretanto, contrapondo ao modelo institucional do SUS, destaco algumas situações limitantes presentes nesse processo de organização da gestão regionalizada. Dentre eles, destaca-se a heterogeneidade da estrutura federativa brasileira, que apresenta distinção no desenvolvimento institucional na condução da gestão da saúde.

Seria necessário o fortalecimento das capacidades administrativas e institucionais das esferas de governo. Muitos Estados e a maioria dos Municípios brasileiros não possuem condições para prover de forma autônoma as ações e serviços de saúde necessários para sua população, com escassez de recursos financeiros, materiais e humanos, o que fortalece a interdependência entre os governos.

Destaca-se também, a cultura política do país, com predominância de interesses e conveniências políticas partidárias, resultando em disputas entre os entes nos acordos cooperativos para a regionalização dos serviços de saúde.

Neste cenário, deve ser considerado também o porte dos municípios, ou seja, os mais populosos, mais desenvolvidos economicamente e, consequentemente, com maior concentração de capacidade instalada dos serviços de saúde, possuem maior poder político nas pactuações na região de saúde da qual é integrante. Assim, as regras para as pactuações ficam concentradas nos municípios maiores com maior força política.

A organização dos serviços nas regiões de saúde é coordenada pelos governos estaduais, sendo os municípios parte do processo como entes autônomos. Nesse contexto, cabe uma reflexão sobre a concretização da descentralização dos Estados e Municípios na organização regional da saúde, num cenário onde os conflitos federativos estão presentes, seja no sentido horizontal ou vertical, exigindo a relação intergovernamental para a construção de consensos.

Assim, o compartilhamento de responsabilidades na política de saúde no âmbito regional requer dos entes federados, relações de cooperação, competição, acordos e decisões numa arena de disputa política.

As mudanças recentes, com a edição do Decreto $n^{0}$ 7.508/2011, ressaltam a instituição de um novo formato de articulação federativa para a organização dos serviços de saúde: o contrato organizativo de ação pública da saúde, ato jurídico firmado tripartite União, Estados e Municípios, que explicita os compromissos e prioridades dos entes federativos para uma determinada região de saúde. 
A formalização de contratos entre os entes federados pode ser considerada como importante estratégia de consolidação de relações intergovernamentais, na perspectiva de conformação do planejamento regional integrado, e o adequado funcionamento das instâncias de negociação e pactuação federativa do SUS no âmbito regional: Comissão Intergestores Regionais.

\section{Considerações finais}

A descentralização na política de saúde ocasionou mudanças na caracterização do federalismo, como os arranjos institucionais; interesses regionais; atores; leis e normas do sistema de saúde; arranjos legais para definição de responsabilidades entre os entes federados; transferências fiscais intergovernamentais; e relações horizontais e verticais entre as instâncias de governo.

A regionalização da saúde mostra sua potencialidade para a organização das redes de atenção à saúde, ainda com a necessidade de alguns avanços nas relações regionais da saúde.

As negociações e disputas estabelecidas nas relações intergovernamentais na condução da política de saúde e na organização de redes de atenção podem ter mudanças nas relações de poder e institucionais, a partir dos processos de descentralização e regionalização, desde que ocorra a adequada coordenação interfederativa, com a garantia de relações intergovernamentais com interação, compartilhamento, cooperação e decisão conjunta.

Nesse sentido, entende-se que as atuais mudanças propostas pelo Decreto no 7.508/201 trazem determinações para o aprimoramento das relações federativas, com fortalecimento da capacidade dos entes federados na condução da organização das ações e serviços de saúde no território da região de saúde.

Conclui-se que, neste cenário atual, para consolidar o pacto federativo brasileiro é necessária a efetiva atuação entre os entes federados de forma compartilhada e cooperativa, tornando as disputas e conflitos menos acirrados na estrutura federativa. É necessário que as instâncias de governo ampliem as suas funções para além dos seus limites político-administrativos e, com reforço nas relações intergovernamentais, a atuação alcance o âmbito regional, de forma a garantir o acesso aos serviços de saúde. 


\section{Referências}

1. Brasil. Constituição da República Federativa do Brasil de 1988. Disponível em http://www.planalto.gov.br/ccivil_03/Constituicao/Constituicao.htm. [Acesso em: 05 nov 2012.

2.Abrucio, FL. Os baroões da federação: os governadores e a redemocratização brasileira. São Paulo: Editora Hucitec, Departamento de Ciência Política da USP, 1998.

3. Reverbel, CED. O Federalismo numa visão tridimensional do Direito. Porto Alegre: Livraria do Advogado Editora, 2012.

4. Weichert, MA. O Sistema Único de Saúde no Federalismo Brasileiro. Revista de Direito Constitucional e Internacional, v. 32, 2000, p. 154.

5. Meirelles, HL. Direito municipal brasileiro. São Paulo: Saraiva, 2006.

6. Dourado, DA; Dallari, SG; Elias, PEM. Federalismo Sanitário Brasileiro: perspectiva da regionalização no Sistema Único de Saúde. São Paulo, 2012.

7. Lecowitz, E; Lima, LDM, Vieira C. Política de saúde nos anos 90: relações intergovernamentais e papel das Normas Operacionais Básicas. In: Revista Ciência e Saúde Coletiva. Rio de Janeiro, v. 6, n. 2, 2001

8. Viana, ALD; Lima, LD Regionalização e relações federativas na política de saúde do Brasil. Rio de Janeiro: Editora Contra Capa, 2011.

9. Goulart, F. Descentralização e Regionalização do SUS na década de 1990. Redes e regionalização em saúde no Brasil e na Itália: lições aprendidas e contriguições para o debate. Organização Pan-Americana da Saúde. Brasília, 2011.

10. Machado, CV. Direito Universal e Política Nacional: o papel do Ministério da Saúde na política de saúde brasileira de 1990 a 2002. Rio de Janeiro: Museu da República, 2007.

11. Brasil. Regionalização solidária e cooperativa: orientações para sua implementação no SUS. Série Pacto pela Saúde, v.3. Brasília: Ministério da Saúde, 2006.

12. Brasil. Decreto n. 7.508 de 28 de junho de 2011. Regulamenta a Lei n. 8.080 de 19 de setembro de 1990, para dispor sobre a organização do Sistema Único de Saúde - SUS, o planejamento da saúde, a assistência à saúde, a articulação interfederativa, e dá outras providências. Disponível em: < http://www.planalto.gov.

br/ccivil_03/_ato2011-2014/2011/decreto/D7508.htm>. [Acesso em: 5 nov.2012]

Recebido em: 5.6.2017

Aprovado em: 21.6.2017

\section{Como citar este artigo:}

Curvina ACC. A regionalização da saúde no federalismo brasileiro. Revista Cadernos Ibero-Americanos de Direito Sanitário. 2017 abr./jun, 6(2):42-57. 